\title{
Transfusion thresholds: the dangers of guidelines based on randomized controlled trials
}

\author{
Jean-Louis Vincent ${ }^{*}$ (i)
}

(C) 2020 Springer-Verlag GmbH Germany, part of Springer Nature

A task force of the European Society of Intensive Care Medicine (ESICM) recently reported its consensus recommendations on optimal blood transfusion practices [1]. This was a challenging exercise for them: On the one hand, randomized controlled trials (RCTs) are supposed to give the most reliable answer to any question related to optimal treatments; on the other hand, RCTs that use a strategy based only on hemoglobin $(\mathrm{Hb})$ thresholds cannot provide a sufficient guide. The authors preferred not to offer a clinical perspective, but rather to review the literature that indicates that strategies based on different $\mathrm{Hb}$ concentrations do not result in different mortality rates.

However, the decision to transfuse should not be based only on $\mathrm{Hb}$ concentrations [2]. To take illustrative extremes, a Hb concentration of $8 \mathrm{~g} / \mathrm{dL}$ may be perfectly acceptable in a young, fit person recovering from trauma, but can be worrisome in a patient with persisting, profound shock or an elderly patient with a history of a myocardial infarction and significant tachycardia. How can we characterize this complex decision process? This is a very difficult question. When we designed the protocol of the $\mathrm{ABC}$ study quite a long time ago [3], we had long discussions about possible indications for blood transfusion that could complement the $\mathrm{Hb}$ level, and finally opted for the vague terms 'altered tissue perfusion,' 'coronary artery disease,' 'diminished physiological reserve' and 'other indications': We could not propose anything better. Today we may even also consider the role of anemia in intensive care unit (ICU)-acquired weakness and difficulty rehabilitating frail patients.

${ }^{*}$ Correspondence: jlvincent@intensive.org

Department of Intensive Care, Erasme University Hospital, Université libre de Bruxelles, Route de Lennik 808, 1070 Brussels, Belgium
The investigator may prefer to transfuse a patient rather than to enroll them in the proposed RCT where the strategy is based on a $\mathrm{Hb}$ threshold. In the landmark Canadian study by Hebert et al. [4], 87\% of potentially eligible patients could not be enrolled, and the trial had to be stopped earlier than scheduled for slow enrollment. In general, numerous exclusions decrease the external validity of an RCT.

Moreover, in these trials that include heterogeneous populations, it is likely that some patients enrolled in the liberal transfusion group will benefit from the transfusion, whereas other patients who do not really need it will be harmed by it. Likewise, among patients enrolled in the restrictive strategy group, some may benefit from the non-exposure to unnecessary blood and others (e.g., with coronary artery disease) may be harmed, so that the overall outcome in the study will show no difference between the two arms (Fig. 1). The same scenario can be repeated in the multitude of studies addressing the question of transfusion, as well as in many other negative RCTs on interventions that can have both beneficial and harmful effects, such as sepsis therapies, including corticosteroids, or different levels of positive end-expiratory pressure in acute respiratory distress syndrome (ARDS) [5].

Restrictive transfusion strategies may be well tolerated in less sick patients, but may be very risky in critically ill patients. A reanalysis of the initial study by Hebert et al. revealed a harmful effect of restrictive transfusion strategy in patients with ischemic heart disease and in those with high APACHE scores [6]. In a large RCT in patients after cardiac surgery, Murphy et al. [7] reported a significantly higher number of deaths in the restrictive than in the liberal transfusion group ( 4.2 vs. $2.6 \%$,

\section{实




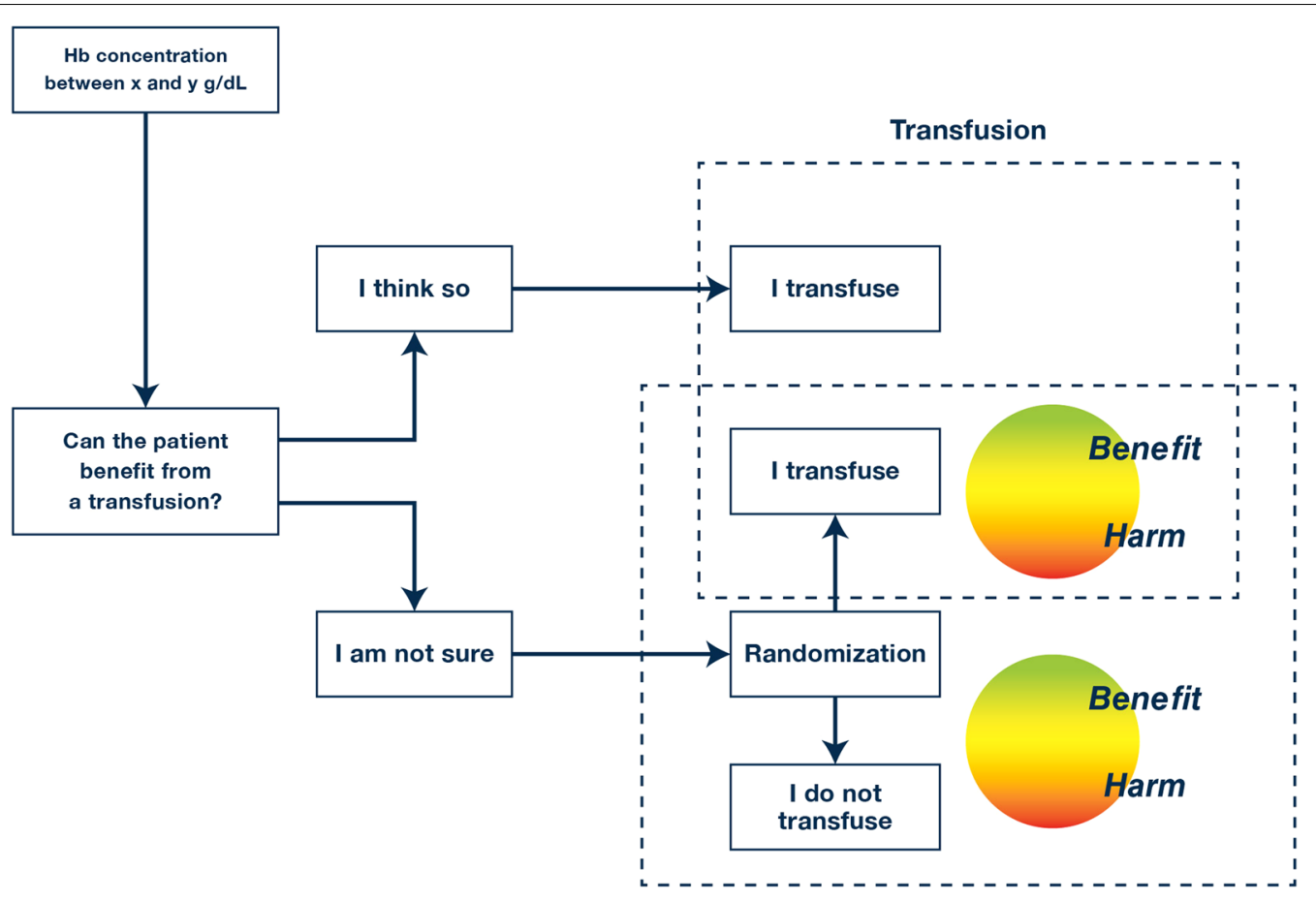

Clinical trial

Fig. 1 Approach of randomized controlled trials on blood transfusion strategies based on hemoglobin concentrations

$p<0.05)$. Another RCT on transfusions after cardiac surgery reported a larger incidence of cardiogenic shock in elderly patients who received fewer transfusions [8]. A Brazilian study reported a higher mortality rate in critically ill patients with cancer managed with a liberal transfusion strategy compared to those managed with a restrictive strategy [9]. There are only two RCTs available in patients with sepsis. One study by Holst et al. [10] reported no difference in mortality, but a transfusion was given to virtually all patients in one group $(98.8 \%)$ vs. still about two-thirds (63.9\%) in the other group. The other, smaller study [11] showed that a liberal transfusion strategy was associated with a lower 90-day mortality rate (59 vs. $70 \%, p=0.03)$.

Strict application of guidelines such as those from the ESICM Taskforce based on RCTs that used only $\mathrm{Hb}$ as a trigger may be dangerous for patients. It would mean that doctors would no longer be needed to evaluate the need for transfusion: A simple link between the hematology laboratory and the blood bank would be sufficient. This is everything but personalized medicine! The answer to the question of optimal transfusion strategies could come from large observational studies, which have the advantage of including every single patient without exclusion. Data from large databases from Korea [12] as well as the SOAP [13] and ICON [14] studies have indicated that liberal blood transfusion strategies in critically ill patients may be associated with improved outcomes. The RCT gurus will say that even the best propensity analysis cannot take all factors into account, but I will counter that RCTs based on $\mathrm{Hb}$ concentrations cannot take into account all the factors that can and should influence the medical decision to transfuse. Big data could provide valuable answers to which factors should be used to guide transfusion and artificial intelligence will help us make better decisions than ones simply based on Hb concentrations, which are, after all, a very crude marker.

\section{Compliance with ethical standards}

\section{Conflicts of interest}

JLV has no conflicts of interest to declare.

\section{Publisher's Note}

Springer Nature remains neutral with regard to jurisdictional claims in published maps and institutional affiliations.

Received: 27 November 2019 Accepted: 29 November 2019

Published online: 7 January 2020

\section{References}

1. Vlaar A, Oczkowski S, de Bruin S, Wijnberge M, Antonelli M, Aubron C, Aries P, Duranteau J, Juffermans NP, Meier J, Murphy GJ, Abbasciano R, Muller M, Shah A, Perner A, Rygaard S, Walsh TS, Guyatt G, Dionne J, Cecconi M (2019) Transfusion strategies in non-bleeding critically ill adults: 
a clinical practice guideline from the European Society of Intensive Care Medicine. Intensive Care Med (in press)

2. Sakr Y, Vincent JL (2015) Should red cell transfusion be individualized? Yes. Intensive Care Med 41:1973-1976

3. Vincent JL, Baron JF, Reinhart K, Gattinoni L, Thijs L, Webb A, Meier-Hellmann A, Nollet G, Peres-Bota D (2002) Anemia and blood transfusion in critically ill patients. JAMA 288:1499-1507

4. Hebert PC, Wells G, Blajchman MA, Marshall J, Martin C, Pagliarello G, Tweeddale M, Schweitzer I, Yetisir E (1999) A multicenter, randomized, controlled clinical trial of transfusion requirements in critical care. Transfusion Requirements in Critical Care Investigators, Canadian Critical Care Trials Group. N Engl J Med 340:409-417

5. Santacruz CA, Pereira AJ, Celis E, Vincent JL (2019) Which multicenter randomized controlled trials in critical care medicine have shown reduced mortality? A systematic review. Crit Care Med 67:1680-1691

6. Deans KJ, Minneci PC, Suffredini AF, Danner RL, Hoffman WD, Ciu X, Klein HG, Schechter AN, Banks SM et al (2007) Randomization in clinical trials of titrated therapies: unintended consequences of using fixed treatment protocols. Crit Care Med 35:1509-1516

7. Murphy GJ, Pike K, Rogers CA, Wordsworth S, Stokes EA, Angelini GD, Reeves BC (2015) Liberal or restrictive transfusion after cardiac surgery. N Engl J Med 372:997-1008

8. Nakamura RE, Vincent JL, Fukushima JT, de Almeida JP, Franco RA, Lee PC, Osawa EA, Pinto Silva CM, Costa Auler JOJ et al (2015) A liberal strategy of red blood cell transfusion reduces cardiogenic shock in elderly patients undergoing cardiac surgery. J Thorac Cardiovasc Surg 150:1314-1320
9. de Almeida JP, Vincent JL, Galas FR, de Almeida EP, Fukushima JT, Osawa EA, Bergamin F, Park CL, Nakamura RE et al (2015) Transfusion requirements in surgical oncology patients: a prospective, randomized controlled trial. Anesthesiology 122:29-38

10. Holst LB, Haase N, Wetterslev J, Wernerman J, Guttormsen AB, Karlsson S, Johansson PI, Aneman A, Vang ML et al (2014) Lower versus higher hemoglobin threshold for transfusion in septic shock. N Engl J Med 371:1381-1391

11. Bergamin FS, Almeida JP, Landoni G, Galas FRBG, Fukushima JT, Fominskiy E, Park CHL, Osawa EA, Diz MPE et al (2017) Liberal versus restrictive transfusion strategy in critically ill oncologic patients: the transfusion requirements in critically ill oncologic patients randomized controlled trial. Crit Care Med 45:766-773

12. Park DW, Chun BC, Kwon SS, Yoon YK, Choi WS, Sohn JW, Peck KR, Kim YS, Choi YH et al (2012) Red blood cell transfusions are associated with lower mortality in patients with severe sepsis and septic shock: a propensitymatched analysis. Crit Care Med 40:3140-3145

13. Vincent JL, Sakr Y, Sprung C, Harboe S, Damas P (2008) Are blood transfusions associated with greater mortality rates? Results of the sepsis occurrence in acutely ill patients study. Anesthesiology 108:31-39

14. Vincent JL, Jaschinski U, Wittebole X, Lefrant JY, Jakob SM, Almekhlafi GA, Pellis T, Tripathy S, Rubatto Birri PN et al (2018) Worldwide audit of blood transfusion practice in critically ill patients. Crit Care 22:102 